\title{
RELAXATION OF A RELATIVISTIC ELECTRON BEAM IN PLASMA IN THE TRAPPING REGIME
}

\author{
I.V. Timofeev, K.V. Lotov \\ Budker Institute of Nuclear Physics, 630090, Novosibirsk, Russia; \\ Novosibirsk State University, 630090, Novosibirsk, Russia
}

A model for collective relaxation of high-power relativistic electron beams in plasmas is proposed, which describes beam-plasma interaction in the regime when amplitudes of unstable waves are large enough to trap beam electrons. The model predicts profiles of energy release along the plasma column in a good quantitative agreement with experimental measurements.

PACS: 52.40.Mj, 52.35.Qz, 52.50.Gj

\section{INTRODUCTION}

The beam-plasma interaction is one of the most fundamental problems of plasma physics, which is of great importance for both space and laboratory plasmas. Due to beam-plasma instabilities, the beam can excite high-amplitude electric fields in the plasma and lose significant part of the energy. This property is used to heat the plasma in mirror traps. This study is motivated by recent progress in plasma heating at GOL-3 facility [1].

The conventional method to attack the problem of relativistic electron beam relaxation in a plasma for typical mirror trap parameters is based on the theory of weak turbulence (see review [2] and references therein). It is usually assumed that many unstable modes with random phases are excited. In the problem of stationary injection of the beam into the plasma-filled half-space, these modes grow until their energy is saturated either by the wave drift out of the relaxation region, or by some nonlinear processes in plasma (three-wave interaction or wave scattering on plasma particles). However, the applicability of the weak turbulence is sometimes questionable. It turns out that the assumption of random phases is not always valid. For large amplitudes, correlation effects should be taken into account. The correlations are caused by the wave-to-wave interaction either due to the strong plasma nonlinearity (strong turbulence), or by means of common resonant particles, if the beam response to the electric field of the wave is nonlinear. As shown in numerical simulations of nonrelativistic beam relaxation [3], the correlation effects become important if the condition $\Gamma>k \Delta v$ is fulfilled, where $\Gamma$ is the instability growth rate, $\Delta v=\sqrt{e \varphi_{0} / m}$ is the width of the region in velocity space in which beam electrons (of the charge -e and mass $\mathrm{m}$ ) are trapped by the wave potential of the typical amplitude $\varphi_{0}$. Under this condition, waves with close phase velocities, such that the velocity difference is smaller than $\Delta v$, form coherent wave packets. Since the condition of trapping is fulfilled for typical mirror trap parameters, the goal of this paper is to propose the model describing the beam relaxation problem in the trapping regime.

\section{EFFECT OF TRAPPING ON EXCITATION OF RESONANT WAVES}

Let us consider the stationary injection of a monoenergetic electron beam with the relativistic factor $\gamma$, density $n_{b}$ and initial angular spread $\Delta \theta_{0}$ into the half-space filled by the plasma of the density $n$. The beam propagates along the magnetic field $\mathrm{B}$ such that $\omega_{B e} \approx \omega_{p e}$, where $\omega_{B e}=e B /(m c)$ is the electron cyclotron frequency, $\omega_{p e}=\sqrt{4 \pi e^{2} n / m}$ is the electron plasma frequency, and $c$ is the speed of light. We develop a one-dimensional model.

Let us distinguish single-mode and multi-mode regimes of wave excitation. The single-mode regime is realized for almost monoenergetic beams $\left(\Delta v_{b} \leq \Delta v\right)$. In this case, all beam particles are in resonance with a single unstable mode, and trapping effects become essential if the density of the wave energy $W$ and the width of the trapping region $\Delta v$ exceed the following values [5]:

$$
W_{0} \approx \gamma^{2} n_{b} m v^{2}\left(n_{b} / n\right)^{1 / 3}, \Delta v \approx v / \gamma\left(n_{b} / n\right)^{1 / 3},
$$

where $v$ is the average velocity of the beam. While at the beginning of the interaction the beam has a narrow energy spectrum, at later times it excites different modes, their number increases with the increase of the velocity spread $\Delta v_{b}$, and the regime changes to the multi-mode one. Since the trapping regime is characterized by the formation of wave packets with the trapping width $\Delta v$, it is natural to divide the wide beam $\left(\Delta v_{b}>\Delta v\right)$ into microbeams with the density $\bar{n}_{b} \approx n_{b}\left(\Delta v / \Delta v_{b}\right)$ which interact with their own wave packets. The expression for the trapping width in the multimode regime can be found from the condition $\Gamma \approx k \Delta v=\omega_{p e} \Delta v / v$ with the growth rate $\Gamma$ calculated in the hydrodynamic approximation for each microbeam

$$
\begin{aligned}
& \Gamma \approx \omega_{p e} / \gamma\left(\overline{n_{b}} / n\right)^{1 / 3} . \text { It yields } \\
& \qquad \Delta v \approx v\left(n_{b} / \gamma^{3} n\right)^{1 / 2}\left(v / \Delta v_{b}\right)^{1 / 2} .
\end{aligned}
$$

In the initial value problem [5], the systematic energy exchange between beam particles and plasma waves ends as the trapping effects come into play. In the problem of steady-state injection, the wave packet energy continues to grow after it exceeds the trapping threshold, but the rate of this growth is significantly lower as compared to 
the exponential stage. In the single-mode regime, the density of the energy flux $q$ transported by the beam decreases after passage through the wave packet of the length $l \approx v /(k \Delta v)$ by the value $\Delta q \approx \gamma^{3} n_{b} m c^{2} \Delta v$ that corresponds to the average deceleration of beam electrons by $\Delta v$. So, we can find the scaling of the pump power $P$ (i.e., the rate of packet energy growth) on the energy density in this packet:

$$
P=\frac{d W}{d t} \approx \frac{\Delta q}{l} \propto \Delta v^{2} \propto W^{1 / 2}
$$

Thus, in the regime $W>W_{0}$ the pump power weakly depends on the energy of the wave packet. The influence of trapping effects on the pump power can be illustrated by the qualitative dependence $P(W)$ (Fig.1).

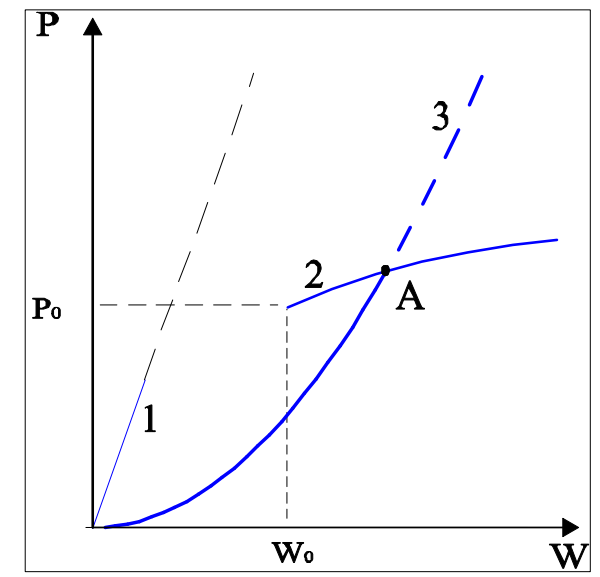

Fig. 1. The dependence of the pump power $P$ on the average energy density in the packet W(1 - the linear pump, 2 - the pump modified by trapping effects, 3 - the nonlinear sink)

\section{THE MODEL OF BEAM RELAXATION}

The weak energy dependence of the pump power allows us to simplify the model of beam relaxation, as compared to the weak turbulence model. Namely, in the trapping regime we do not need to know the nature of nonlinear mechanisms responsible for the energy sink out of the resonant waves. The power of beam energy losses remains close to $P_{0}$ no matter at what level the wave energy is really saturated (point "A") by nonlinear processes.

In the trapping regime, beam electrons interact with a large number of wave packets. Assume that after the passage through each packet, electrons get a random change in velocity $\Delta v_{1}=\alpha \Delta v$, where $\Delta v$ is the trapping width determined by the right-hand side of (2) and $\alpha \approx 1$ is a numerical coefficient used to improve this estimate formula. Thus, beam electrons diffuse in the energy space so that in a time $\Delta t \approx 1 /\left(k \Delta v_{1}\right)$ the change in electron energy is $\Delta \varepsilon \approx \gamma^{3} m v \Delta v_{1}$. We can introduce the diffusion equation

$$
\bar{v} \frac{d \Delta \varepsilon_{b}^{2}}{d z}=\frac{\Delta \varepsilon^{2}}{\Delta t}=\alpha^{3} \omega_{p e} m^{7 / 2}\left(\frac{n_{b}}{n}\right)^{3 / 2} \frac{\bar{\gamma}^{6-7} v^{3 / 2}}{\Delta \varepsilon_{b}},
$$

where $\Delta \varepsilon_{b}$ is the energy spread of the beam. We also assume that, with the random change in velocity $\Delta v_{1}$, electrons get a regular deceleration of the same order. That is why the average "longitudinal" beam energy $\bar{\gamma} m c^{2}$ decreases with the increase in the energy spread:

$$
\bar{\gamma} m c^{2}=\bar{\gamma}_{0} m c^{2}-\frac{\Delta \varepsilon_{b}(z)-\Delta \varepsilon_{b}(0)}{2} .
$$

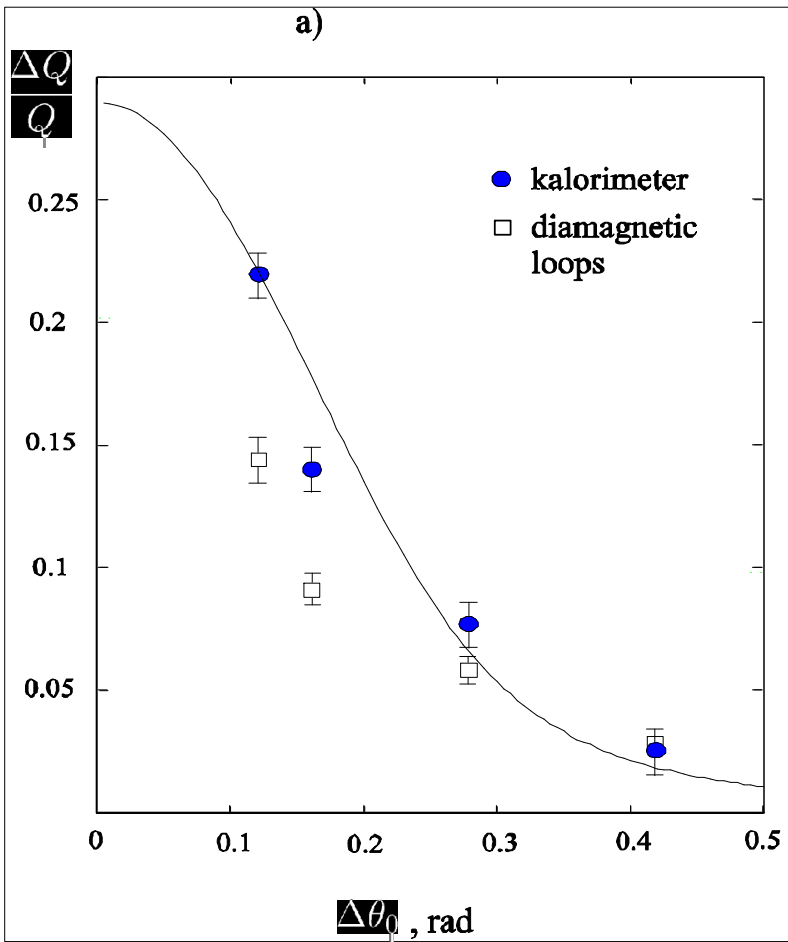

b)

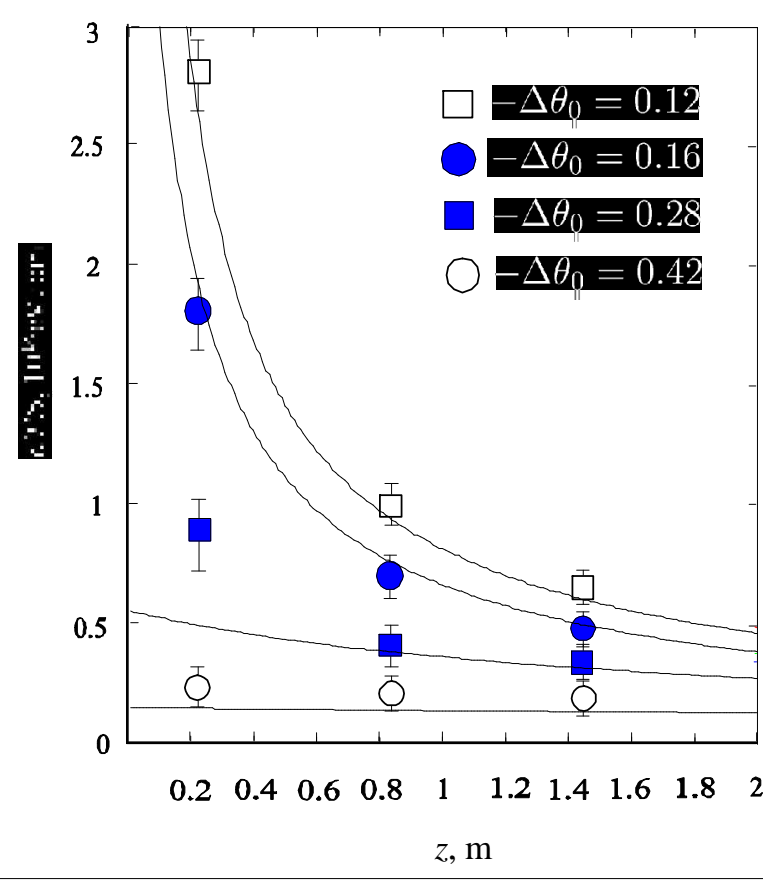

Fig. 2. The dependence of the energy fraction lost by the beam in the plasma on the initial angular spread of the beam $\Delta \theta_{0}$ : a) experimental data from [4] (dots) and the model dependence (7) (solid line) for $\alpha=0.29$; $b$ ) The profiles of plasma diamagnetism for different angular spreads (dots, from [4]) and corresponding model profiles (solid lines - the formula (8)) 
Given the z-dependence of the average beam energy (5), we can derive the power of beam losses along the plasma column:

$$
P(z)=-\frac{d}{d z}\left(\overline{\mathrm{v}} n_{b} \bar{\gamma} m c^{2}\right)
$$

\section{THE COMPARISON WITH EXPERIMENTS}

The proposed model predicts z-profiles of beam energy losses and their dependence on different beam and plasma parameters [6]. The influence of the initial angular spread of the beam on the relaxation efficiency was studied in experiments [4] at INAR facility (Fig.2). The best agreement between experimental measurements and theoretical prediction for the fraction of total energy lost by the beam in the plasma column of the length $\mathrm{L}$

$$
\frac{\Delta Q}{Q}=\frac{\bar{\gamma}_{0}}{(\gamma-1)}\left[1-\sqrt{\frac{\bar{\gamma}^{2}(L)-1}{\bar{\gamma}_{0}{ }^{2}-1}}\right],
$$

is achieved for the fitting parameter $\alpha=0.29$ (Fig.2a). We can also compare the longitudinal profiles of plasma diamagnetism measured for different initial angular spreads of the beam. The model prediction is given by the expression

$$
n T(z) S=\frac{2}{3} \eta \tau_{b} S P(z),
$$

where $\mathrm{T}$ is the plasma electron temperature, $\mathrm{S}$ is the cross section of the plasma column, $\tau_{b}$ is the duration of beam injection and $\eta$ is the fraction of the lost energy remained in the plasma. We can take $\eta$ from the experiment (Fig.2a) as the ratio of the total energy content measured by diamagnetic loops and the total beam energy losses measured by calorimeter. There is a good quantitative agreement between the theory and experiments (Fig.2b). It should be particularly emphasized that this agreement is achieved without any additional fitting parameters.

\section{REFERENCES}

1. V.S.Koidan, A.V.Arzhannikov, V.T.Astrelin et al.// Trans. Fusion Technol. 2005, v. 47, p. 35.

2. B.N.Breizman. Reviews of Plasma Physics/ ed. by B.B. Kadomtsev, N-Y: "Cosultants Bureau", 1990, v.15, p. 61.

3. Yu.S. Sigov. Computer Simulation: The Link between Past and Future of Plasma Physics (composed by V.D. Levchenko and G.I. Zmievskaya). Moscow: "Nauka", 2001 (in Russian).

4. A.V. Arzhannikov, A.V. Burdakov, V.S. Koidan, V.V. Konuykhov, K.I. Mekler, A.I. Rogozin // Pis'ma Zh. Exp. Teor. Fiz. 1978, v. 27, p. 173 [JETP Lett. 1978, v. 27, p. 161].

5. Ya.B. Fainberg, V.D. Shapiro, V.I. Shevchenko // Zh. Exp. Teor. Fiz. 1969, v. 57, p. 966 [ Sov. Phys. JETP 1970, v. 30, p. 528].

6. I.V. Timofeev, K.V. Lotov // Phys. Plasmas 2006, v. 13(6), p. 062312.

\section{РЕЛАКСАЦИЯ РЕЛЯТИВИСТСКОГО ЕЛЕКТРОННОГО ПУЧКА В ПЛАЗМЕ В РЕЖИМЕ ЗАХВАТА}

\section{И.В. Тимофеев, К.В. Лотов}

Предложена модель коллективной релаксации мощного релятивистского электронного пучка, описывающая взаимодействие пучка с плазмой в режиме, при котором энергия неустойчивых колебаний оказывается достаточной для захвата электронов пучка. Модель предсказывает профили энерговыделения пучка в плазме по длине установки, которые находятся в хорошем количественном согласии с экспериментальными данными.

\section{РЕЛАКСАЦІЯ РЕЛЯТИВІСТСЬКОГО ЕЛЕКТРОННОГО ПУЧКА В ПЛАЗМІ У РЕЖИМІ ЗАХОПЛЕННЯ}

\section{І.В. Тимофсєв, К.В. Лотов}

Запропоновано модель колективної релаксації потужного релятивістського електронного пучка, яка описує взаємодію пучка з плазмою в режимі, при якому енергія нестійких коливань виявляється достатньої для захоплення електронів пучка. Модель передбачає профілі енерговиділення пучка в плазмі по довжині установки, які знаходяться в гарній кількісній згоді з експериментальними даними. 